\title{
Strategies for Endovascular Aortic Repair in Aortobronchial and Aortoesophageal Fistulas
}

\author{
Bernhard Dorweiler ${ }^{1}$ Ernst Weigang ${ }^{1}$ Friedrich Duenschede ${ }^{1}$ Michael Bernhard Pitton ${ }^{2}$ \\ Christoph Dueber ${ }^{2}$ Christian-Friedrich Vahl ${ }^{1}$
}

\author{
${ }^{1}$ Division of Vascular Surgery, Department of Cardiothoracic and \\ Vascular Surgery, University Medical Center, Johannes-Gutenberg \\ University, Mainz, Germany \\ 2 Department of Radiology, University Medical Center, Johannes- \\ Gutenberg University, Mainz, Germany
}

\begin{abstract}
Address for correspondence Bernhard Dorweiler, MD, PhD, Division of Vascular Surgery, Department of Cardiothoracic and Vascular Surgery, University Medical Center, Johannes-Gutenberg University, Langenbeckstr. 1, 55101 Mainz, Germany (e-mail: dorweiler@htg.klinik.uni-mainz.de).
\end{abstract}

Thorac Cardiovasc Surg 2013;61:575-580.

\begin{abstract}
Keywords

- descending aorta

- aortobronchial fistula

- aortoesophageal fistula

- endovascular repair

Objective To report our experience of thoracic endovascular aortic repair (TEVAR) for acute bleeding originating from the thoracic aorta in patients with aortobronchial fistula (ABF) or aortoesophageal fistula (AEF).

Patients and Methods A total of nine patients (three woman) were treated from September 1995 to March 2012 by TEVAR for $\operatorname{ABF}(n=5)$ and $\operatorname{AEF}(n=4)$. The implants $(N=14)$ were introduced with fluoroscopic guidance via the aorta $(n=1)$, the iliac $(n=2)$, or femoral $(n=11)$ artery, respectively.

Results All aortic lesions could be sealed successfully. Perioperative morbidity was $0 \%$ in the $\mathrm{ABF}$ group and $50 \%$ ( 2 of 4 ) in the AEF group and no procedure-related morbidity was noted except one patient who received aortofemoral reconstruction because of iliac occlusive disease. After an overall mean follow-up of 56 months, three patients of the ABF group are alive and well and two patients died of nonrelated cause. Of the AEF group, one patient is alive after 22 months, and one died from metastasized esophageal cancer after 7 months.

Conclusion TEVAR is a safe and reliable procedure in the management of ABF. For AEF, TEVAR provides a successful first-line treatment to seal the fistula and control bleeding. However, prognosis is limited by the esophageal lesion and by ongoing mediastinitis/ sepsis.
\end{abstract}

\section{Introduction}

Aortobronchial fistula (ABF) and aortoesophageal fistula (AEF) are rare but potentially life-threatening complications of both treated and untreated aortic disease due to exsanguinating hemorrhage. By classification, primary fistulas occur as communications between the untreated aorta and the bronchial tree/esophagus due to aneurysm rupture, penetrating aortic ulcer, advanced esophageal or lung cancer, or ingestion of foreign body. Secondary fistulas originate from reconstructed aorta (prosthetic graft) or develop secondary to complications of a visceral surgical procedure (anastomotic insufficiency). ${ }^{1}$

received

March 11, 2013

accepted after revision

April 29, 2013

published online

July 4, 2013

Compared with results of open surgery for thoracic aortic aneurysm (TAA) with a mortality of $14 \%,{ }^{2}$ open aortic surgery in $A B F$ and $A E F$ is endowed with a significantly increased mortality of $24^{3}$ and $50 \%,{ }^{4}$ respectively, clearly reflecting the complexity of those lesions. Therefore, less invasive concepts to reduce perioperative mortality have been evaluated with special attention on thoracic endovascular aortic repair (TEVAR). Since the first report of TEVAR in TAA (13 patients) in $1994,{ }^{5}$ the technique has rapidly evolved and currently is the primary recommendation for treatment of aneurysms of the thoracic aorta. ${ }^{6}$ Although until today, no randomized trials of open versus endovascular TEVAR have been performed.

(c) 2013 Georg Thieme Verlag KG Stuttgart · New York
DOI http://dx.doi.org/ 10.1055/s-0033-1347294. ISSN 0171-6425. 
Evidence has accumulated that there are advantages of TEVAR over open repair in terms of survival in the short term. ${ }^{2}$

Therefore, the objective of this study was to analyze our results of TEVAR in the treatment of $A B F$ and AEF.

\section{Patients and Methods}

Between September 1995 and March 2012, nine patients (three women, six men) with a mean age of $65 \pm 12$ years (range, 48-80 years) were treated by endovascular stent graft placement in the thoracic aorta (TEVAR) for ABF or AEF. For the subsequent report, patients are divided into an $A B F$ group $^{1-5}$ and an AEF group ${ }^{6-9}$ (-Table 1). Preoperative imaging protocol consisted of high-resolution spiral computed tomography (CT) scan and additional magnetic resonance image in selected cases. Preprocedural planning was based on $3 \mathrm{D}$ reconstructions obtained with the Aquarius workstation (TeraRecon, Frankfurt, Germany). For postprocedural imaging analysis (2D maximum intensity projection and 3D volume rendering), the OSIRIX software (Pixmeo SARL, Geneva, Switzerland) was used. At our institution, endovascular treatment is performed by an interdisciplinary approach of vascular surgeons and interventional radiologists. Informed consent was obtained either by the patients themselves or by the relatives for the remaining cases. The implan- tation procedures were performed according to standard protocol in a hybrid operating room equipped with a ceiling-mounted digital subtraction angiography (Siemens Artis Zee, Erlangen, Germany). All cases were operated with standby for cardiopulmonary bypass available, in case a conversion to open procedure would be necessary. The operations were in most cases performed under general anesthesia and ABF patients were intubated with a double lumen tube to allow for selective ventilation of the nondiseased lung. In selected cases, cardiac overpacing (180 bpm) was used to reduce blood flow during deployment of the graft.

The follow-up protocol encompassed clinical visit with repetitive high-resolution contrast-enhanced spiral CT scans with early and late phase series and a chest X-ray after 1, 3, 6, and 12 months with annual repetitions thereafter.

\section{Results}

According to the above-described method, we have implanted 14 stent grafts in the descending aorta in a series of nine patients (-Tables $\mathbf{1}$ and $\mathbf{2}$ ). The mean operative time for the TEVAR procedure including surgical arterial access and arterial closure was $124 \pm 54$ minutes (range, 65-200 min). For Patient 3, operative time was prolonged to 315 minutes because of difficult access and aortofemoral reconstruction,

Table 1 Perioperative patient data

\begin{tabular}{|c|c|c|c|c|c|c|}
\hline Pat. & Gender & Age & Diagnosis & History & Location of fistula & Follow-up \\
\hline 1 & Male & 48 & $\mathrm{ABF}, \mathrm{II}$ & $\begin{array}{l}\text { Anastomotic pseudoaneur- } \\
\text { ysm after repair of aortic } \\
\text { coarctation (patch 1967, } \\
\text { tube-graft 1968) }\end{array}$ & Left upper segment bronchus & $\begin{array}{l}\text { Alive at } 188 \text { months, Re- } \\
\text { TEVAR in } 2004\end{array}$ \\
\hline 2 & Male & 77 & $A B F, I$ & TAA $(5 \mathrm{~cm})$ & Left lower segment bronchus & $\begin{array}{l}\text { Nonrelated death (age } 82 \text { ) } \\
\text { at } 61 \text { months }\end{array}$ \\
\hline 3 & Female & 61 & $A B F, I$ & PAU & Left bronchial mainstem & Alive at 151 months \\
\hline 4 & Male & 74 & $A B F, I$ & PAU & Left lower segment bronchus & $\begin{array}{l}\text { Nonrelated death (colon } \\
\text { cancer) at } 10 \text { months }\end{array}$ \\
\hline 5 & Male & 80 & $\mathrm{ABF}, \mathrm{I}$ & Postdissection TAA $(6.5 \mathrm{~cm})$ & Left lower segment bronchus & Alive at 3 months \\
\hline 6 & Female & 60 & $\mathrm{AEF}, \mathrm{I}$ & $\begin{array}{l}\text { Malignant fistula of metas- } \\
\text { tasized esophageal cancer, } \\
\text { palliative treatment }\end{array}$ & & $\begin{array}{l}\text { Died after } 7 \text { months (tu- } \\
\text { mor cachexia) }\end{array}$ \\
\hline 7 & Male & 71 & AEF, II & $\begin{array}{l}\text { Anastomotic insufficiency } \\
\text { with aortic erosion after } \\
\text { esophageal resection for } \\
\text { esophageal cancer (pT2B } \\
\text { pN1 M0) }\end{array}$ & & $\begin{array}{l}\text { Died on day of TEVAR } \\
\text { (sepsis/multiorgan failure) }\end{array}$ \\
\hline 8 & Male & 68 & AEF, II & $\begin{array}{l}\text { Anastomotic insufficiency } \\
\text { with aortic erosion after } \\
\text { esophageal resection for } \\
\text { esophageal cancer (pT1B } \\
\text { pN0 M0) }\end{array}$ & & $\begin{array}{l}\text { Died after } 3 \text { months (in } \\
\text { hospital) due to recurrent } \\
\text { sepsis/pneumonia }\end{array}$ \\
\hline 9 & Female & 48 & AEF, I & $\begin{array}{l}\text { Ruptured mycotic aneurysm } \\
\text { of distal thoracic aorta due } \\
\text { to Boerhaave Syndrome } \\
\text { with esophageal perforation }\end{array}$ & & $\begin{array}{l}\text { Alive at } 22 \text { months, Re-TE- } \\
\text { VAR (prox. extension) at } 3 \\
\text { months }\end{array}$ \\
\hline
\end{tabular}

Abbreviations: ABF, aortobronchial fistula; AEF, aortoesophageal fistula; I, primary fistula; II, secondary fistula; Pat., patient; PAU, penetrating aortic ulcer; prox., proximal; Re-TEVAR, redo-thoracic endovascular aortic repair; TAA, thoracic aortic aneurysm. 
Table 2 Stent graft details

\begin{tabular}{|c|c|c|c|c|c|c|c|}
\hline Graft & Pat. & Device & Size $(\mathrm{mm})$ & Arterial access & $\begin{array}{l}\text { Landing zone } \\
(0-4)\end{array}$ & Anesthesia & Comments \\
\hline 1 & \multirow[t]{2}{*}{1} & Stentor & $26 \times 50$ & External iliac & 4 & General & $\begin{array}{l}\text { Iliac access due to } \\
\text { shortness of introduc- } \\
\text { er sheath }\end{array}$ \\
\hline 2 & & Talent & $30 \times 100$ & Common femoral & 3 & Local & $\begin{array}{l}\text { Proximal and distal } \\
\text { extension for recur- } \\
\text { rent ABF at } 96 \text { months }\end{array}$ \\
\hline 3 & \multirow[t]{2}{*}{2} & Talent & $36 \times 130$ & $\begin{array}{l}\text { Aortofemoral } \\
\text { graft (PTFE } 10 \text { mm) }\end{array}$ & 3 & General & \\
\hline 4 & & Talent & $36 \times 110$ & Femoral (PTFE graft) & 3 & General & $\begin{array}{l}\text { Distal extension for } \\
\text { recurrent } A B F \text { at } 5 \\
\text { months }\end{array}$ \\
\hline 5 & 3 & Vanguard & $24 \times 50$ & Common femoral & 3 & General & \\
\hline 6 & 4 & Talent & $30 \times 110$ & Common femoral & 4 & General & \\
\hline 7 & 5 & Relay NBS plus & $34 \times 154$ & Common femoral & 3 & Local & \\
\hline 8 & 6 & Valiant & $28 \times 150$ & External iliac & 3 & General & \\
\hline 9 & \multirow[t]{3}{*}{7} & Valiant & $38 \times 160$ & \multirow[t]{3}{*}{ Common femoral } & \multirow[t]{3}{*}{3} & \multirow[t]{3}{*}{ General } & \multirow{3}{*}{$\begin{array}{l}\text { Bail-out procedure in } \\
\text { general surgery OR } \\
\text { using plain fluorosco- } \\
\text { py (C-arm) }\end{array}$} \\
\hline 10 & & Valiant & $42 \times 150$ & & & & \\
\hline 11 & & Valiant & $42 \times 150$ & & & & \\
\hline 12 & 8 & Valiant & $32 \times 150$ & Common femoral & 3 & General & \\
\hline 13 & \multirow[t]{2}{*}{9} & Valiant & $32 \times 130$ & Common femoral & 4 & General & $\begin{array}{l}\text { Simultaneous visceral } \\
\text { debranching }\end{array}$ \\
\hline 14 & & Relay plus & $28 \times 215 \times 20$ & Common femoral & 3 & General & $\begin{array}{l}\text { Tapered graft for } \\
\text { proximal extension at } \\
3 \text { months }\end{array}$ \\
\hline
\end{tabular}

Abbreviations: NBS, nonbare stent; Pat., patient; PTFE, polytetrafluoroethylene.

in patient 9, visceral debranching was performed immediately after TEVAR (245 minutes). All patients survived the operative procedure and sealing of the aortic lesion could be achieved in all cases resulting in a technical success rate of the implantation procedure of $100 \%$. Proximal landing zone was located in zone 3 in the majority of cases (-Table 2 ), overstenting of the left subclavian artery has not been performed in this series.

For the ABF group, all five patients recovered and were discharged home from the hospital, resulting in a perioperative mortality of $0 \%$. In the long-term follow-up, two patients are alive and well after 188 and 151 months, respectively. Two patients died after 61 and 10 months, respectively, because of nonrelated causes. In two cases, ${ }^{1,2}$ redo TEVAR had to be performed for recurrent hemoptysis at 5 and 96 months (-Fig. 1). Interestingly, both patients continued to expectorate bits of hematoma for 2 weeks, after which no further episodes of expectoration were noted. The procedure-related morbidity was found to be one of the five patients: in Patient 2 , conversion from femoral to iliac and finally to aortic access had to be performed because of extensive iliac occlusive disease. For introduction of the stent device, a $10-\mathrm{mm}$ polytetrafluoroethylene conduit was used and completed to an aortofemoral bypass at the end of the procedure. Thrombosis, embolization, or clinical manifestations of impeded blood flow as well as postoperative stroke or paraplegia could not be detected. Completion angiograms and postoperative CT scan confirmed satisfactory position of the implanted stent graft in each case and showed no sign of endoleak or dislocation. All patients were transferred to the intensive care unit for postoperative monitoring, and prolonged duration of mechanical ventilation (9 days) was only necessary for Patient 3 because of cardiopulmonary arrest and underlying chronic obstructive pulmonary disease. Patients were either discharged home, ${ }^{2}$ retransferred to the referring hospital, ${ }^{1}$ or discharged into rehabilitation. ${ }^{2}$ All patients with $\mathrm{ABF}$ received long-term oral antibiotic treatment (broad-spectrum gyrase inhibitor) for 6 weeks postoperatively. Complete resolution of the extensive periaortic hematoma was noted in Patient $3 .^{7}$

For the AEF group, only one patient ${ }^{9}$ is alive after 22 months (-Fig. 2). This patient presented with a ruptured aortic aneurysm at the thoracoabdominal level that in retrospection was attributed to an esophageal perforation (Boerhaave Syndrome). Following emergency TEVAR and visceral debranching (superior mesenteric and splenic artery with vein graft), the esophageal lesion was sealed with a stent as bridging procedure and the mediastinal abscess was drained. After 3 months, removal of the stent and esophageal resection was performed. The patient recovered from the procedure and could be discharged home but had to be readmitted for dilatation of a stenosis of the esophagogastric anastomosis repeatedly. However, no recurrent hematemesis or aortic endoleak could be 


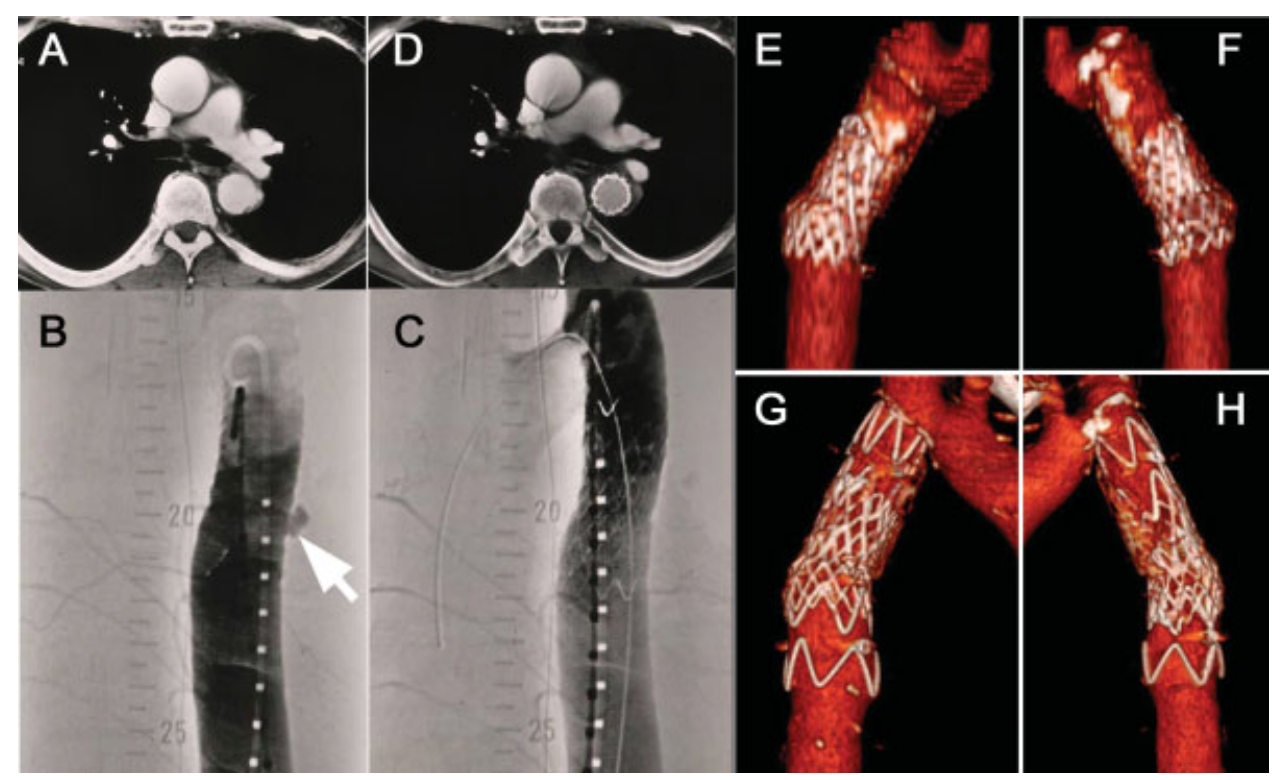

Fig. 1 Male patient aged 48-year-old presenting with hemoptysis and history of 2x aortic surgery (patch/tube graft) for coarctation during childhood. Computed tomography (CT) and digital subtraction angiography detect small pseudoaneurysm at the site of previous aortic surgery (A, B). TEVAR using first generation implant (Stentor, MinTec, Freeport, Bahamas) successfully sealed the lesion (C, D). At 96 months, patient presented with recurrent hemoptysis and material fatigue was evident in CT (E, F). Aortic relining was performed (Talent, Medtronic, Minneapolis, Minnesota, United States) and at 188 months, Stentor and Talent grafts are in situ without signs of dislocation or recurrent hemoptysis (G, H).

detected at 22 months after the initial TEVAR. Two patients with secondary fistula (aortic erosion because of anastomotic insufficiency and mediastinitis following esophageal resection for esophageal cancer, Patients 7 and 8) died in hospital. One shortly after TEVAR (day 1), the other after recurrent episodes of sepsis/pneumonia due to persisting esophagobronchial fistula despite combined esophageal and bronchial stent placement in multiorgan failure 3 months after TEVAR.
In Patients 7 to 9, bronchial lavages/drainage specimen revealed multiple gram-positive bacteria and candida species. Therefore, all patients received calculated broad-spectrum antibiotics (third generation cephalosporin + gyrase inhibitor) in hospital. Patient 9 was discharged with a gyrase inhibitor until readmission for esophageal resection. The fourth patient with $\mathrm{AEF}^{6}$ was treated in a palliative situation of metastasized esophageal cancer $(25 \mathrm{~cm}$ from the mouth/
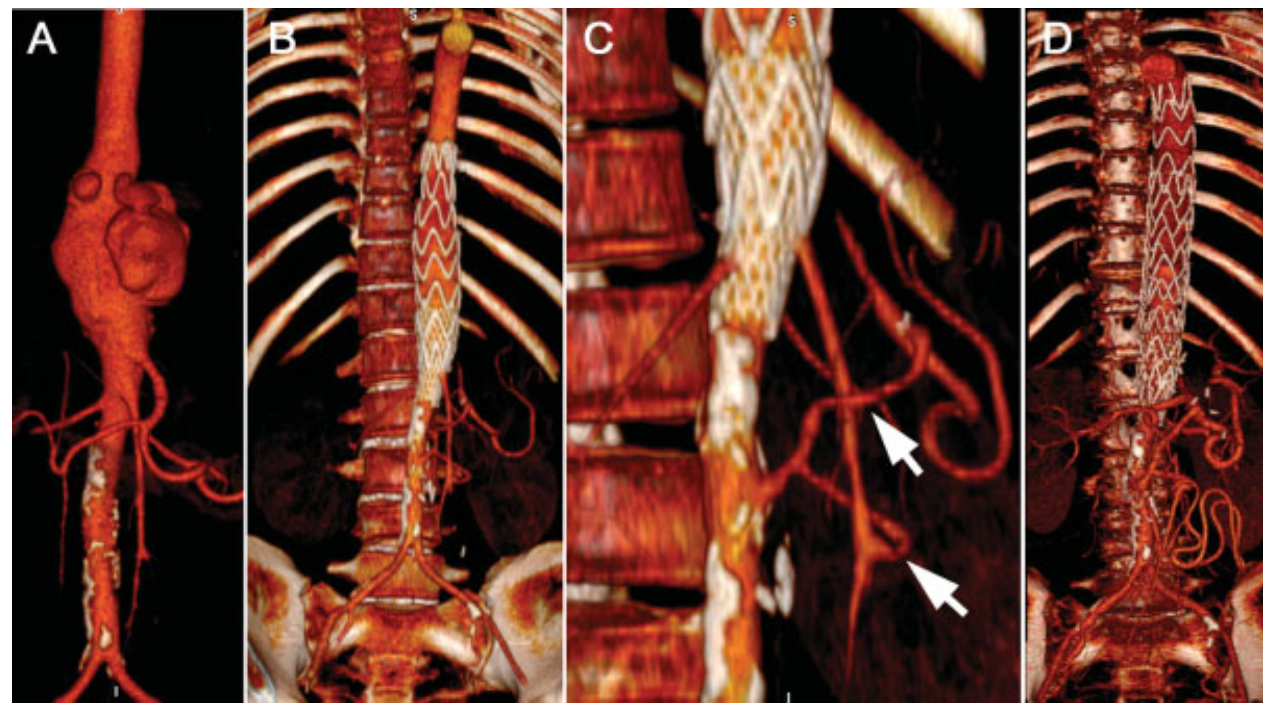

Fig. 2 Female patient aged 48-year-old presenting with hematemesis and epigastric/chest pain. Computed tomography (CT) shows ruptured aneurysm of distal thoracic aorta due to Boerhaave symdrome (A). Emergency TEVAR (Medtronic Valiant $32 \times 130 \mathrm{~mm}$ ) (B) and subsequent visceral revascularization with aortosplenic (upper arrow) and aortomesenteric (lower arrow) bypasses (greater saphenous vein, C) was performed. Follow-up CT at 22 months shows stent graft in place (after proximal extension with Bolton Relay BS $28 \times 215 \times 20 \mathrm{~mm}$ after $3 \mathrm{mo}$ ) and patent visceral bypass grafts (D). 
teeth) and died 7 months postoperatively in a nursing home because of tumor cachexia.

\section{Discussion}

Treatment of ABF and AEF aims at two major goals: immediate control of aortic bleeding and closure of the fistula. The first, however, puts high requirements on logistics for an open operation that are often not easily met. $^{8}$ Consequently, as TEVAR has the advantage of rapid aortic sealing at low invasiveness, attempts were undertaken to adopt TEVAR in the treatment of ABF. In 1996, the first two successful cases of TEVAR in ABF were reported by Campagna et al and Chuter et al. ${ }^{9,10}$ Since then, the technique has been used more widely, however, single center series are very limited because of the low incidence of ABF and AEF. Currently, there are two articles that focus on the outcomes of TEVAR in ABF and AEF: Jonker et al conducted a literature survey and identified 71 cases of ABF and 43 cases of AEF with an in-hospital mortality of 3\% and $19 \%$, respectively, and a mean follow-up of 10 months. ${ }^{11}$ Chiesa et al published a multicenter study where 25 cases of $A B F,{ }^{13}$ $\mathrm{AEF}{ }^{11}$ and both $\mathrm{ABF} / \mathrm{AEF}^{1}$ were pooled from 17 centers. Here, 30-day overall mortality was high (56\%) and not different between $\mathrm{ABF}$ and $\mathrm{AEF}$ and follow-up was 22.6 months. ${ }^{12}$ From both series, it clearly emerges that $\mathrm{ABF}$ and $\mathrm{AEF}$ are distinct entities, which require different treatment modalities.

With respect to ABF, additional evidence has been accumulated, which corroborates safety and also long-term efficacy of TEVAR: Riesenman et al published their institutional series of 5 cases and added a literature survey yielding a total of 67 cases ( 4 reports with $n \geq 5$ ) with an overall 30-day mortality of $1.5 \%$ and mean follow-up of 21.5 months. ${ }^{13}$ De Rango et al compiled a total number of 87 cases ( 3 reports with $n \geq 5$ ), however, no overall analysis of mortality and follow-up was performed. ${ }^{14}$ Throughout the cited publications, mean/median follow-up did not exceed 42.6 months. The largest single-center series $(n=11)$ of TEVAR in ABF also stated beneficial results with safe and effective management (0\% mortality), however, follow-up was limited to 8.8 months. ${ }^{15}$ Our previously published results of patients treated by TEVAR for $\mathrm{ABF}^{7,16,17}$ were in line with those data and we have now expanded our series to five patients with a mean follow-up of 82.6 months, which represents the longest currently available single-center follow-up for this patient entity. All of the patients survived, and there was only minor procedure-related morbidity (aortofemoral bypass for access in severe iliac occlusive disease).

Since the first report of TEVAR in a patient with AEF by Oliva, ${ }^{18}$ the current series in the literature, as reviewed by Jonker et al, consists of 43 cases in total. ${ }^{11}$ However, institutional series is limited to a few cases, with the report by Topel et al probably being the most extensive $(n=5) .{ }^{1}$ In addition, multicenter studies from European centers are available that report series of 11 patients with TEVAR in AEF. ${ }^{12}$ As mentioned above, prognosis of AEF differs largely from that of ABF. In-hospital mortality of TEVAR in AEF patients ranges from $19 \%$ in the meta-analysis ${ }^{11}$ to $31 \% .{ }^{12}$ However, reports of open surgery in AEF are even more sparse and in one of the larger series, published by Kieffer in 2003, perioperative mortality is $50 \% .{ }^{4}$ Therefore, TEVAR in that setting has been added to the armamentarium of vascular surgeons to serve as a "bridge" to open surgical repair ${ }^{19}$ and should be regarded as a first choice lifesaving procedure as it is able to control the life-threatening bleeding. ${ }^{8}$ Of the four AEF cases presented in the series, one is caused by an infiltration of the metastasized esophageal carcinoma into the descending aorta (malignant fistula). In that case, patient's comorbidity was prohibitive of primary open surgical repair as well as secondary esophageal resection. TEVAR in case of primary malignancy-induced AEF has also been described before, ${ }^{20}$ although survival was limited to 3 months due to recurrent bleeding complication. In our case, patient was able to be discharged to nursing home and suffered death from tumor-induced cachexia after 7 months, however, without recurrent episodes of bleeding.

It has been highlighted, that key element of treatment in AEF patients is correction of esophageal lesion ${ }^{8,19}$ as survival of AEF patients without esophageal surgery is significantly limited. ${ }^{1,11}$ Placement of esophageal stents has emerged as a valuable tool, however, unlike aortic stent grafts, in our patients they were not able to seal the lesion completely and therefore cannot exclude risk of mediastinitis. Based on our results, definitive surgical correction seems vital to obtain a reasonable long-term perspective and possible techniques include esophageal resection with gastric pull-up, esophagoplasty, or the "Thal" fundoplication.

In summary, we were able to successfully control acute bleeding from the descending thoracic aorta due to $\mathrm{ABF}$ and AEF in a series of nine patients applying endovascular treatment techniques (TEVAR). Our results with $0 \%$ perioperative mortality for the ABF-group compare well the literature and our follow-up of 82.6 months is the longest published so far. Consequently, TEVAR can be seen as safe, reliable, and durable treatment of $A B F$ without the actual need for secondary conversion (removal of stent graft). ${ }^{21}$ In our experience, even for recurrent hemoptysis (because of material fatigue), redo TEVAR seems justified. For AEF, TEVAR also provides a straightforward method to achieve bleeding control by aortic sealing. However, the accompanying esophageal lesion is limiting the long-term prognosis by recurrent sepsis and therefore, TEVAR and esophageal stenting should be considered a bridging procedure to open surgery in those patients. However, it must be subjected to further evaluation, if an aortic conversion operation (e.g., endograft replacement by homograft, ${ }^{1}$ or pericardium $^{22}$ ) indeed is necessary, or if the endograft can remain in situ and only the esophageal lesion is targeted.

\section{Conflict of Interest}

None.

\section{References}

1 Topel I, Stehr A, Steinbauer MG, Piso P, Schlitt HJ, Kasprzak PM. Surgical strategy in aortoesophageal fistulae: endovascular stentgrafts and in situ repair of the aorta with cryopreserved homografts. Ann Surg 2007;246(5):853-859 
2 Cheng D, Martin J, Shennib H, et al. Endovascular aortic repair versus open surgical repair for descending thoracic aortic disease a systematic review and meta-analysis of comparative studies. J Am Coll Cardiol 2010;55(10):986-1001

3 Favre JP, Gournier JP, Adham M, Rosset E, Barral X. Aortobronchial fistula: report of three cases and review of the literature. Surgery 1994;115(2):264-270

4 Kieffer E, Chiche L, Gomes D. Aortoesophageal fistula: value of in situ aortic allograft replacement. Ann Surg 2003;238(2):283-290

5 Dake MD, Miller DC, Semba CP, Mitchell RS, Walker PJ, Liddell RP. Transluminal placement of endovascular stent-grafts for the treatment of descending thoracic aortic aneurysms. N Engl J Med 1994;331(26):1729-1734

6 Hiratzka LF, Bakris GL, Beckman JA, et al. M. 2010 ACCF/AHA/AATS/ ACR/ASA/SCA/SCAI/SIR/STS/SVM guidelines for the diagnosis and management of patients with Thoracic Aortic Disease. Circulation 2010;121:e266-e369

7 Pitton MB, Duber C, Neufang A, Schlegel J. Endovascular repair of a non-contained aortic rupture caused by a penetrating aortic ulcer. Cardiovasc Intervent Radiol 2002;25(1):64-67

8 Verhoeven EL, Vourliotakis G. Thoracic endovascular aortic repair for aortobronchial or aortoesophageal fistulas: permanent or temporary salvage or not an option at all? J Endovasc Ther 2009;16(4):441-442

9 Campagna AC, Wehner JH, Kirsch CM, et al. Endovascular stenting of an aortopulmonary fistula presenting with hemoptysis. A case report. J Cardiovasc Surg (Torino) 1996;37(6):643-646

10 Chuter TAM, Ivancev K, Lindblad B, Brunkwall J, Arén C, Risberg B. Endovascular stent-graft exclusion of an aortobronchial fistula. J Vasc Interv Radiol 1996;7(3):357-359

11 Jonker FH, Schlösser FJ, Moll FL, et al. Outcomes of thoracic endovascular aortic repair for aortobronchial and aortoesophageal fistulas. J Endovasc Ther 2009;16(4):428-440

12 Chiesa R, Melissano G, Marone EM, Kahlberg A, Marrocco-Trischitta MM, Tshomba Y. Endovascular treatment of aortoesopha- geal and aortobronchial fistulae. J Vasc Surg 2010;51(5): 1195-1202

13 Riesenman PJ, Brooks JD, Farber MA. Thoracic endovascular aortic repair of aortobronchial fistulas. J Vasc Surg 2009;50(5):992-998

14 De Rango P, Estrera AL, Azizzadeh A, Safi HJ. Stent-graft repair of aortobronchial fistula: a review. J Endovasc Ther 2009;16(6): 721-732

15 Bailey CJ, Force S, Milner R, Kasirajan K, Veeraswamy RK. Thoracic endovascular repair as a safe management strategy for aortobronchial fistulas. J Vasc Surg 2011;53(5):1202-1209, discussion 1209

16 Dorweiler B, Dueber C, Neufang A, Schmiedt W, Pitton MB, Oelert $\mathrm{H}$. Endovascular treatment of acute bleeding complications in traumatic aortic rupture and aortobronchial fistula. Eur J Cardiothorac Surg 2001;19(6):739-745

17 Pitton MB, Herber S, Schmiedt W, Neufang A, Dorweiler B, Düber C. Long-term follow-up after endovascular treatment of acute aortic emergencies. Cardiovasc Intervent Radiol 2008;31(1): 23-35

18 Oliva VL, Bui BT, Leclerc G, et al. Aortoesophageal fistula: repair with transluminal placement of a thoracic aortic stent-graft. J Vasc Interv Radiol 1997;8(1 Pt 1):35-38

19 Allen RC, Sebastian MG. The role of endovascular techniques in aortoesophageal fistula repair. J Endovasc Ther 2001;8(6): 602-603

20 Feezor RJ, Hess PJ, Lee WA. Endovascular treatment of a malignant aortoesophageal fistula. J Vasc Surg 2009;49(3):778

21 Böckler D, Schumacher H, Schwarzbach M, Ockert S, Rotert H, Allenberg JR. Endoluminal stent-graft repair of aortobronchial fistulas: bridging or definitive long-term solution? J Endovasc Ther 2004;11(1):41-48

22 Czerny M, von Allmen R, Opfermann P, et al. Self-made pericardial tube graft: a new surgical concept for treatment of graft infections after thoracic and abdominal aortic procedures. Ann Thorac Surg 2011;92(5):1657-1662 